\title{
Effect of ornidazole on fertility of male rats: inhibition of a glycolysis-related motility pattern and zona binding required for fertilization in vitro
}

\author{
W. Bone ${ }^{1,3}$, N. G. Jones ${ }^{2}$, G. Kamp ${ }^{3}$, C. H. Yeung ${ }^{1}$ and T. G. Cooper ${ }^{1 *}$ \\ Institutes of ${ }^{1}$ Reproductive Medicine, ${ }^{2}$ Organic Chemistry and ${ }^{3}$ Zoophysiology of the University, Münster, Germany
}

\begin{abstract}
The effects of the male antifertility agent ornidazole on glycolysis as a prerequisite for fertilization were investigated in rats. Antifertility doses of ornidazole inhibited glycolysis within mature spermatozoa as determined from the lack of glucose utilization, reduced acidosis under anaerobic conditions and reduced glycolytic enzyme activity. As a consequence, cauda epididymidal spermatozoa from ornidazolefed rats were unable to fertilize rat oocytes in vitro, with or without cumulus cells, which was not due to transfer of an inhibitor in epididymal fluid with the spermatozoa. Under IVF conditions, binding to the zona pellucida was reduced in spermatozoa from ornidazole-fed males and the spermatozoa did not undergo a change in swimming pattern, which was observed in controls. The block to fertilization could be explained by the disruption of glycolysis-dependent events, since reduced binding to the zona pellucida and a lack of kinematic changes were demonstrated by control spermatozoa in glucose-free media in the presence of respiratory substrates. The importance of glycolysis for binding to, and penetration of, the zona pellucida, and hyperactivation in rats is discussed in relation to the glycolytic production of ATP in the principal piece in which local deprivation of energy may explain the reduced force of spermatozoa from ornidazole-fed males.
\end{abstract}

\section{Introduction}

Ornidazole exerts a rapid and reversible antifertility effect in male rats (McClain and Downing, 1988a,b; Oberländer et al., 1994; Cooper et al., 1997). In dogs, humans and rats, one of the metabolites of ornidazole is the C3-chloro side-chain of the nitroimidazole ring (Schwartz et al., 1979; Jones and Cooper, 1996) which may produce 3-chlorolactaldehyde and $\alpha$-chlorohydrin, known inhibitors of the glycolytic enzymes glyceraldehyde 3-phosphate dehydrogenase (GAPDH) and triosephosphate isomerase (TPI) in spermatozoa (Jones et al., 1981; Jones and Stevenson, 1983; Stevenson and Jones, 1985). In accordance with this view, Oberländer et al. (1996) reported a $32 \%$ inhibition of GAPDH and a 52\% inhibition of TPI activities in spermatozoa when male rats were administered $400 \mathrm{mg}$ ornidazole per $\mathrm{kg}$ per day for 10 days. Therefore, the infertility action of ornidazole appears to be a result of its effect on the ability of spermatozoa ultimately to obtain ATP by the glycolytic pathway. A reduction in kinematic parameters in spermatozoa from ornidazoletreated rats could only be observed when spermatozoa were released into medium containing glucose as the only

${ }^{*}$ Correspondence.

Received 15 April 1999. substrate (Yeung et al., 1995; Cooper et al., 1997), but not when pyruvate and lactate were also added (Yeung et al., 1995), indicating that ornidazole affects the utilization of glucose.

As pyruvate and lactate are present in uterine and oviductal secretions (Leese, 1988), which may maintain sperm motility and ATP concentrations (Ford and Harrison, 1987) despite glycolytic inhibition, the infertility of ornidazole-fed males is unlikely to be a consequence of reduced sperm motility. This view is supported by the observation that a similar number of spermatozoa reach the oviductal ampulla of females mated with ornidazole- or vehicle-treated males (Yeung et al., 1995). Nevertheless, as no fertilization occurred under these conditions, ornidazole must have brought about a fertilization block in the ampulla, other than that due to reduced progressive motility. Therefore, ornidazole and $\alpha$-chlorohydrin could affect other sperm functions by reducing glycolysis.

The present study was conducted (i) to demonstrate the effect of the incomplete inhibition of GAPDH and TPI after ornidazole treatment in rats (Oberländer et al., 1996) on glycolytic turnover in spermatozoa and (ii) to investigate the consequences of a glycolytic block on the fertilization of rat gametes in vitro. 


\section{Materials and Methods}

\section{Chemicals, animals and treatments}

All reagents were from Sigma (Deisenhofen) unless otherwise stated. Male (350-450 g) and female (180-220 g) Sprague-Dawley rats from Charles River Wiga $\mathrm{GmbH}$ (Sulzfeld) were housed under $12 \mathrm{~h}$ light:12 h dark (lights on 07:00 h) at $22^{\circ} \mathrm{C}$ and $50 \%$ relative humidity and had access to standard chow (Altrumin $\mathrm{GmbH}$, Lage) and water ad libitum. Male rats were fed $400 \mathrm{mg}$ ornidazole $\mathrm{kg}^{-1}$ once a day by oral gavage between $08: 00 \mathrm{~h}$ and 10:00 h for 14 days and controls were fed vehicle alone $(0.2 \%(\mathrm{w} / \mathrm{v})$ carboxymethylcellulose in water plus two drops Tween 20 per $100 \mathrm{ml}$ ) during the same time period.

\section{Collection of spermatozoa for estimation of glycolytic activity}

After feeding rats ornidazole or vehicle for 14 days, the males were killed by cervical dislocation. Spermatozoa were obtained by retrograde flushing over $15 \mathrm{~min}$ through a PVC cannula (i.d. $0.5 \mathrm{~mm}$, o.d. $0.8 \mathrm{~mm}$; Critchley Electrical Products Pty Ltd, Silverwater, NSW) tied into the vas deferens and collected into a positive displacement pipette from a cut end of the tubule in the mid-cauda epididymidis. Flushing medium was warmed $\left(37^{\circ} \mathrm{C}\right)$ medium $\mathrm{G}$ (Cooper et al., 1997) for enzyme measurements or nuclear magnetic resonance (NMR) medium $\left(90 \mathrm{mmol} \mathrm{NaCl} \mathrm{l}^{-1}, 4.78 \mathrm{mmol} \mathrm{KCl}\right.$ $\mathrm{l}^{-1}, 1.71 \mathrm{mmol} \mathrm{CaCl}_{2} \mathrm{l}^{-1}, 1.19 \mathrm{mmol} \mathrm{MgSO}_{4} \mathrm{l}^{-1}, 27.07 \mathrm{mmol}$ $\mathrm{NaHCO}_{3} \mathrm{l}^{-1}, 10 \mathrm{mmol}$ Hepes $\mathrm{l}^{-1}, 21.58 \mathrm{mmol}$ sodium lactate $\mathrm{l}^{-1}, 0.5 \mathrm{mmol}$ sodium pyruvate $\mathrm{l}^{-1}, 4 \mathrm{mg} \mathrm{BSA} \mathrm{ml}^{-1}, 5 \mathrm{mmol}$ phenylphosphonate $\mathrm{l}^{-1}$; osmolality $305 \mathrm{mmol} \mathrm{kg}^{-1}, \mathrm{pH}$ 7.2). After release, sperm concentration was estimated by nephelometry at $405 \mathrm{~nm}$ (Spectromax 250, Molecular Devices, Sunnyvale, CA) against a standard curve constructed by volumetric determination in a Neubauer improved chamber.

\section{Measurement of sperm enzyme activities}

The activities of two glycolytic enzymes (GAPDH: EC 1.2.1.12 and TPI: EC 5.3.1.1) known to be inhibited by $\alpha$ chlorohydrin within intact spermatozoa were measured. The activity of hexokinase (EC 2.7.1.1) was also quantified to determine whether there was a non-specific detrimental effect on sperm enzymes. Enzyme activities were measured in sperm sonicates (KLN Ultraschallgenerator, Heppenheim (5 mm probe tip) and Vibracell ${ }^{\mathrm{TM}}$, Sonics and Materials Inc, Danbury ( $3 \mathrm{~mm}$ probe tip); $25 \mathrm{~W}, 20 \mathrm{kHz}, 3 \times 7 \mathrm{~s}$, held on ice between) and assayed by photometry modified from Bergmeyer (1974) (GAPDH, hexokinase) and Ford et al. (1981) (TPI). For measurement of hyaluronidase (EC 3.2.1.35), the released sperm suspensions in medium $G$ $(500 \mu \mathrm{l})$ were centrifuged for $7 \mathrm{~min}$ at $800 \mathrm{~g}$ through $5 \%(\mathrm{w} / \mathrm{v})$ Ficoll in medium $\mathrm{G}$. The washed sperm pellet was resuspended in $1 \mathrm{ml}$ medium $\mathrm{G}$ and frozen for $3 \mathrm{~h}$ at $-20^{\circ} \mathrm{C}$. After thawing, the cells were diluted and the concentration was estimated as described above. Enzyme activity was measured by the method of Dorfman (1955) in which the
$\beta$-N-acetylhexosamine-[1 $\rightarrow 4]$ and $\beta$-glucuronic acid $[1 \rightarrow 3]$ glycosidic bonds are hydrolysed by the enzyme to be assayed, which reduces the extent of complexing of hyaluronic acid to albumin which is measured by turbidimetry at $600 \mathrm{~nm}$. All enzyme assays were modified to be measured in 96-well plates.

\section{NMR spectroscopy for estimation of glycolytic turnover}

Glycolysis in spermatozoa under anaerobic conditions leads to an acidosis of spermatozoa, which results in an acidification of the exogenous medium (Hochachka and Mommsen, 1983; Smith et al., 1985; Büsselmann, 1998). ${ }^{31} \mathrm{P}-$ NMR spectroscopy was conducted using phenylphosphonate as a reference substance for $\mathrm{pH}$ changes in the medium, to estimate the glycolytic activity of spermatozoa. ${ }^{13} \mathrm{C}-\mathrm{NMR}$ spectroscopy was conducted to visualize the glucose consumption and lactate production of spermatozoa.

A Bruker AM 360 spectrometer (Karlsruhe) operating at 145.8 and $90.5 \mathrm{MHz}$ for ${ }^{31} \mathrm{P}$ and ${ }^{13} \mathrm{C}$, respectively, was used for the NMR experiments. Samples were measured in NMR tubes (10 $\mathrm{mm}$ o.d.) without spinning and without field or frequency lock. Spectra were recorded at $37^{\circ} \mathrm{C}$. Spectral parameters for ${ }^{13} \mathrm{C}-\mathrm{NMR}$ and ${ }^{31} \mathrm{P}-\mathrm{NMR}$ were: impulse duration 13.6 and $12.7 \mu$ s, relaxation delay 4 and $2 \mathrm{~s}$, spectral width 22 and $7 \mathrm{kHz}, 32$ and $32 \mathrm{~K}$ data points, acquisition time 0.7 and $2.3 \mathrm{~s}, 250$ and 500 transients and 10 and $10 \mathrm{~Hz}$ line broadening, respectively. ${ }^{13} \mathrm{C}-\mathrm{NMR}$ spectra were obtained with ${ }^{1} \mathrm{H}-\mathrm{CPD},{ }^{31} \mathrm{P}-\mathrm{NMR}$ spectra without ${ }^{1} \mathrm{H}$ decoupling.

${ }^{31} \mathrm{P}-\mathrm{NMR}$ spectra were referenced to endogenous glycerophosphocholine $(\delta=0.5)$, since glycerophosphocholine shows no variation in chemical shift at physiological $\mathrm{pH}$ (Büsselmann, 1998); the phenylphosphonate peak relative to that of glycerophosphocholine was localized at 12 p.p.m. A titration curve was constructed as a standard curve to derive the extracellular $\mathrm{pH}$ from the ${ }^{31} \mathrm{P}-\mathrm{NMR}$ shift. The ${ }^{13} \mathrm{C}-\mathrm{NMR}$ spectra were calibrated against external 3-trimethylsilyl[2,2,3,3D]-1-propionate (TSP).

Spermatozoa from the distal cauda epididymidis of untreated males were treated without glucose (group a) or with $\left[{ }^{13} \mathrm{C}\right]$ glucose $\left(5.56 \mathrm{mmol} \mathrm{l}^{-1}\right)$ (group b). Spermatozoa from ornidazole-treated males after the first recording (group c) were also provided with $5.56 \mathrm{mmol}\left[{ }^{13} \mathrm{C}\right]$ glucose $\mathrm{l}^{-1}$. Spermatozoa were suspended in NMR medium without glucose. Approximately $150 \times 10^{6}$ cells per $2 \mathrm{ml}$ medium were placed in a $10 \mathrm{~mm}$ NMR tube at $37^{\circ} \mathrm{C}$ and an initial ${ }^{31} \mathrm{P}-$ NMR measurement $(t=0 \mathrm{~h})$ was made. After this reading, spermatozoa from groups b and c were given $100 \mu \mathrm{l}$ $\left[{ }^{13} \mathrm{C}\right]$ glucose and ${ }^{13} \mathrm{C}$-NMR spectra were recorded during 7.5 h. Sperm vitality was assessed for incubated spermatozoa using propidium iodide as vital dye.

\section{Sperm vitality}

After the incubations for NMR spectroscopy, $10 \mu \mathrm{l}$ sperm suspension was diluted in $400 \mu \mathrm{l}$ medium G (Oberländer et al., 1994) containing $5 \mu \mathrm{g}$ propidium iodide $\mathrm{ml}^{-1}$ and incubated at ambient temperature for $5 \mathrm{~min}$ in the dark. Approximately 
10000 sperm cells were analysed as dead (propidium iodidepositive) or viable in an EPICS XL flow cytometer (Coulter, Krefeld) by argon laser excitation at $488 \mathrm{~nm}$.

\section{Collection of spermatozoa for IVF}

After 14 days of feeding, males were killed by $\mathrm{CO}_{2}$ asphyxiation and spermatozoa were released by puncturing an excised cauda epididymidis into IVF medium $(94.6 \mathrm{mmol}$ $\mathrm{NaCl} \mathrm{l}^{-1}, 4.78 \mathrm{mmol} \mathrm{KCl} \mathrm{l}^{-1}, 1.71 \mathrm{mmol} \mathrm{CaCl}_{2} \mathrm{l}^{-1}, 1.19 \mathrm{mmol}$ $\mathrm{KH}_{2} \mathrm{PO}_{4} \mathrm{l}^{-1}, 1.19 \mathrm{mmol} \mathrm{MgSO} \mathrm{I}^{-1}, 25.07 \mathrm{mmol} \mathrm{NaHCO}_{3} \mathrm{l}^{-1}, 2$ $\mathrm{mg}$ phenol red $\mathrm{l}^{-1}, 22.9 \mathrm{mmol}$ sodium lactate $\mathrm{l}^{-1}, 0.5 \mathrm{mmol}$ sodium pyruvate $\mathrm{l}^{-1}, 5.55 \mathrm{mmol}$ glucose $\mathrm{l}^{-1}, 50 \mathrm{mg}$ penicillin $\mathrm{l}^{-1}$, $50 \mathrm{mg}$ streptomycin $\mathrm{l}^{-1}, 4 \mathrm{~g} \mathrm{BSA}^{-1}$ ). The tissue was removed after $2 \mathrm{~min}$ and after $15 \mathrm{~min}$ the sperm concentration was measured in triplicate as described above. The sperm suspension was diluted to $2.8 \times 10^{6} \mathrm{ml}^{-1}$ and $800 \mu \mathrm{l}$ was incubated under paraffin oil (BDH, Poole) before co-incubation with oocytes. The method of Toyoda and Chang (1974) was modified by using oocytes recovered from rats with natural oestrous cycles. Female rats were acclimatized for 1 week before the oestrous cycles were monitored by vaginal smears.

\section{Collection of oocytes for IVF}

IVF began between 03:00 $\mathrm{h}$ and 06:00 $\mathrm{h}$ because ovulation occurs about 03:00 h (Shalgi and Kraicer, 1978). Oestrous females were killed with $\mathrm{CO}_{2}$ and oocytes were released within $30 \mathrm{~min}$ from the distal area of the oviductal ampulla by gentle tearing with fine needles. The oocytes with cumuli were transferred to $450 \mu \mathrm{l}$ sterilized $(0.22 \mu \mathrm{m}$ filtered) IVF medium and incubated for $60 \mathrm{~min}$ before co-incubation with spermatozoa. Eggs were maintained at $37^{\circ} \mathrm{C}$ at all times. For fertilization of cumulus-free eggs, eggs were washed and transferred to a Petri dish containing $450 \mu \mathrm{IVF}$ medium and Type $1 \mathrm{~S}$ or Type IV S hyaluronidase $\left(1.5 \mathrm{mg} \mathrm{ml}^{-1}, 480 \mathrm{U} \mathrm{ml}^{-1}\right)$ from bovine testis and gently dispersed to remove granulosa cells without causing mechanical damage to the eggs. After $20 \mathrm{~min}\left(\right.$ at $37^{\circ} \mathrm{C}$ ) the cells were dispersed and hyaluronidase was removed by washing four times for $>60 \mathrm{~min}$ in fresh IVF medium before transfer to the medium under oil for preincubation.

\section{In vitro fertilization}

Diluted sperm suspension $(150 \mu \mathrm{l})$ was transferred to the $450 \mu \mathrm{l}$ IVF dishes containing 5-10 oocytes, giving 700000 spermatozoa $\mathrm{ml}^{-1}$. Gametes were co-incubated for $36 \mathrm{~h}$ when two-cell stage embryos were anticipated (Toyoda and Chang, 1974). At this time, all oocytes and zygotes were transferred to washing medium to remove excess spermatozoa, and the number of two-cell embryos was counted.

\section{Testing epididymal fluid for effects on IVF}

The contents of the distal cauda epididymidis were flushed into $2 \mathrm{ml}$ IVF medium and the sperm concentration was assessed. Sperm suspension $(1 \mathrm{ml})$ was centrifuged through $5 \mathrm{ml}$ of $5 \%(\mathrm{w} / \mathrm{v})$ Ficoll in IVF medium at $700 \mathrm{~g}$ for 7 min at $4^{\circ} \mathrm{C}$ to remove most of the spermatozoa without damage. Completely sperm-free fluid was obtained by further centrifugation at $10000 \mathrm{~g}$ for $7 \mathrm{~min}$ at $4^{\circ} \mathrm{C}$. Approximately $8 \mu \mathrm{l}$ of this supernatant (equivalent to the amount of epididymal fluid containing the same number of spermatozoa used in each IVF insemination) was transferred to the co-culture of eggs and spermatozoa from control animals.

\section{Rat sperm-zona binding}

Spermatozoa from vehicle- and ornidazole-fed rats, collected at 02:00 $\mathrm{h}$ and prepared as described for IVF, were incubated in IVF medium (with or without glucose) at $0.7 \times$ $10^{6} \mathrm{ml}^{-1}$ for $5.5 \mathrm{~h}$ at $37^{\circ} \mathrm{C}$ in $5 \% \mathrm{CO}_{2}$. Sperm suspensions were transferred to $400 \mu \mathrm{l}$ IVF medium containing a maximum of 12 cumulus-free eggs and incubated for $45 \mathrm{~min}$. Oocytes were collected at 05:30 h from two female rats and the granulosa cells were removed with $0.375 \mathrm{mg}$ hyaluronidase $\mathrm{ml}^{-1}$ (280-560 $\mathrm{U} \mathrm{ml}^{-1}$ ) and washed three times before co-incubation with spermatozoa as described above. Eggs were transferred to $100 \mu \mathrm{l}$ PBS containing $0.25 \%$ (v/v) glutaraldehyde and gently shaken in PBS to remove loosely bound spermatozoa, before the number of eggs to which spermatozoa were bound, and the number of spermatozoa bound to the zona pellucida, were recorded. Because primary binding of rat spermatozoa to the zona pellucida is weak, it is possible that spermatozoa were dislodged during this procedure. Therefore, the assay may monitor spermatozoa that are already penetrating the zona pellucida.

\section{Motility of spermatozoa}

As fertilization in vitro occurs between 4 and $6 \mathrm{~h}$ after insemination in rats (Toyoda and Chang, 1974), sperm motility was examined at 2, 4, 6 and $8 \mathrm{~h}$ after release from the epididymis and incubation in $40 \mathrm{ml}$ of IVF medium without covering with oil. Computer-aided sperm analysis (CASA) was performed as described for rats by Yeung et al. (1992) but at $37^{\circ} \mathrm{C}$ and in $80 \mu \mathrm{m}$ chambers (provided by HamiltonThorne) with some modifications for monitoring possible hyperactivated motility (HTM-IVOS version 10.8, $50 \mathrm{~Hz}$, frames analysed $\geq 100$, minimum contrast 10 pixels, minimal size 10 pixels, magnification 0.63 , points per track $40-100)$. A green interference filter (Olympus, IF550) was used in addition to pseudo-dark-field optics provided by an Olympus $\mathrm{BH}-2$ microscope with $\mathrm{a} \times 4$ objective and $\times 20$ phase ring.

The following parameters were measured: curvilinear velocity (VCL, time-average velocity of a sperm head along its actual curvilinear trajectory); average path velocity (VAP, time-average velocity of a sperm head along its spatial average trajectory); straight line velocity (VSL, time-average velocity of a sperm head along the straight line between its first and last detected positions); amplitude of head displacement $(\mathrm{ALH}$, magnitude of lateral displacement of a 
sperm head about its spatial trajectory); beat cross frequency (BCF, time-average rate at which the VCL trajectory crosses the VAP trajectory); linearity (linearity of the curvilinear trajectory $=$ VSL $/$ VCL $\times 100)$; wobble (a measure of the oscillation of the actual trajectory about its spatial average path $=\mathrm{VAP} / \mathrm{VCL} \times 100$ ); and straightness (linearity of the spatial average path $=$ VSL $/$ VAP $\times 100)$.

\section{Statistical analysis}

For each sample, kinematic parameters were expressed as the median of at least 100 spermatozoa per animal. The data in the text and graphs are the mean values of each treatment group. All percentages were transformed by arc-sin squareroot conversion for statistical evaluation and the retransformed values were plotted. Differences in motility and kinematic parameters between treatments were calculated by one-way ANOVA followed by least squared differences or Student-Newman-Keuls methods for multiple comparisons.

\section{Results}

\section{Effects of ornidazole on glycolysis of rat spermatozoa}

Activity of three glycolytic enzymes of rat spermatozoa. Spermatozoa from rats fed ornidazole at $400 \mathrm{mg} \mathrm{kg}^{-1}$ for 14 days showed a reduced activity (mU per $10^{6}$ spermatozoa) compared with controls (mean \pm SEM) of GAPDH $(1.0 \pm 0.15$ versus $7.6 \pm 0.90)$ and TPI $(8.03 \pm 0.80$ versus $26.00 \pm 3.03)$, whereas hexokinase activity was unchanged $(5.93 \pm 0.10$ versus $5.70 \pm 0.19$ ).

${ }^{31} \mathrm{P}-\mathrm{NMR}$ spectroscopy for the measurement of acidosis under anaerobic conditions. Spermatozoa from control rats under anaerobic conditions in medium containing glucose displayed acidosis, as determined by the shift in phenylphosphonate peak towards higher p.p.m. values, indicating a decline in $\mathrm{pH}$ (Fig. 1b, Table 1). However, spermatozoa from ornidazoletreated males incubated under the same conditions did not display acidosis as there was no shift in pH (Fig. 1c, Table 1), yielding results similar to those of control spermatozoa incubated in the absence of glucose (Fig. 1a). The absence of the $\mathrm{pH}$ shift by spermatozoa from the ornidazole-treated rats was not due to cell death, as the percentage of vital cells in medium containing glucose was unchanged, although a decline in vitality of spermatozoa incubated in glucose-free medium was observed after $8 \mathrm{~h}$ of incubation (Table 1).

${ }^{13} \mathrm{C}-\mathrm{NMR}$ measurement for glucose utilization and lactate production. In these experiments, spermatozoa were incubated with $5.56 \mathrm{mmol}\left[{ }^{13} \mathrm{C}\right]$ glucose $\mathrm{l}^{-1}$ as substrate under anaerobic conditions for up to $7.5 \mathrm{~h}$. Control spermatozoa liberated detectable amounts of lactate after $1 \mathrm{~h}$, which increased by $7.5 \mathrm{~h}$ when all of the glucose had been utilized (Fig. 2a). In contrast, production of lactate by spermatozoa from ornidazole-fed rats was markedly reduced even after $7 \mathrm{~h}$ and most of the glucose remained unutilized (Fig. 2b).
Table 1. Acidosis ${ }^{\mathrm{a}}$ and vitality ${ }^{\mathrm{b}}$ of rat sperm cells during anaerobic incubation with and without glucose

\begin{tabular}{lccc}
\hline & \multicolumn{2}{c}{ Controls } & Ornidazole-treated \\
\cline { 2 - 3 } $\begin{array}{l}\text { Duration of } \\
\text { incubation }(\mathrm{h})\end{array}$ & $\begin{array}{c}\text { Without } \\
\text { glucose }\end{array}$ & $\begin{array}{c}\text { With } 5.56 \mathrm{~mol} \\
\text { glucose } \mathrm{l}^{-1}\end{array}$ & $\begin{array}{c}\text { With } 5.56 \mathrm{~mol} \\
\text { glucose } \mathrm{l}^{-1}\end{array}$ \\
\hline $0^{\mathrm{c}}$ & $7.69 \pm 0.13$ & $7.72 \pm 0.03$ & $7.66 \pm 0.03$ \\
$3^{\mathrm{c}}$ & $7.67 \pm 0.17$ & $7.35 \pm 0.03$ & $7.65 \pm 0.04$ \\
$6^{\mathrm{c}}$ & $7.67 \pm 0.16$ & $7.16 \pm 0.04$ & $7.68 \pm 0.04$ \\
$8^{\mathrm{d}}$ & $36.3 \pm 2.70$ & $50.4 \pm 2.40$ & $49.6 \pm 3.40$ \\
\hline
\end{tabular}

Values are mean $\pm \mathrm{SEM}, n=3$.

${ }^{a}$ As determined by the chemical shift of phenylphosphonate in ${ }^{31} \mathrm{P}-\mathrm{NMR}$ spectroscopy.

${ }^{\mathrm{b}}$ As determined from the exclusion of propidium iodide by flow cytometry. 'Results for 0,3 and $6 \mathrm{~h}$ of incubation are $\mathrm{pH}$ values.

${ }^{\mathrm{d}}$ Results for $8 \mathrm{~h}$ of incubation are vitality (\%).

\section{Effects of glycolytic inhibition on the stages of IVF}

Fertilization of rat eggs incubated in vitro. Spermatozoa from four control rats fertilized a mean of $65.4 \pm 8.8 \%$ of 165 cumulus-intact eggs after $36 \mathrm{~h}$ co-incubation, whereas no eggs $(0 / 131)$ were fertilized under the same conditions by spermatozoa from four ornidazole-fed rats. Similarly, although fewer cumulus-free eggs were fertilized by spermatozoa from four control males $(24.2 \pm 7.7 \%$ of 108 ova), no ova $(0 / 109)$ were fertilized by spermatozoa from four ornidazole-fed rats.

Hyaluronidase activity of spermatozoa. Hyaluronidase activity of spermatozoa was unchanged in five males fed ornidazole $\left(6.58 \pm 0.72 \mathrm{U}\right.$ per $10^{6}$ spermatozoa) compared with five males fed vehicle $\left(5.73 \pm 0.75 \mathrm{U}\right.$ per $10^{6}$ spermatozoa).

Effect of contaminating epididymal fluid on fertilization in vitro. There was no inhibitory effect of additional cauda epididymidal fluid from the ornidazole-fed males on the fertility of spermatozoa taken from control males. Spermatozoa from control rats fertilized $34.8 \pm 7.3 \%$ of 80 eggs $(n=4)$ when incubated in IVF medium and $43.1 \pm$ $12.8 \%$ of 76 eggs $(n=4)$ when incubated in the presence of epididymal fluid from an ornidazole-treated male rat.

Number of spermatozoa associated with eggs. When spermatozoa from control males $(n=6)$ were used, $26.5 \%$ of 147 eggs contained spermatozoa within the perivitelline space or vitellus, whereas no sperm tails were observed within the zona pellucida of 76 eggs examined in four experiments using spermatozoa from ornidazole-fed males.

Sperm binding to the zona pellucida. Sperm released from vehicle-fed rats preincubated (capacitated) for $5.5 \mathrm{~h}$ in complete IVF medium bound $45 \mathrm{~min}$ later at their acrosomal region to the zona pellucida (Fig. 3, inset). Fifty-four of the 80 oocytes had more than four spermatozoa attached with a maximum of 69 spermatozoa bound to the zona. Most of the 
(a)
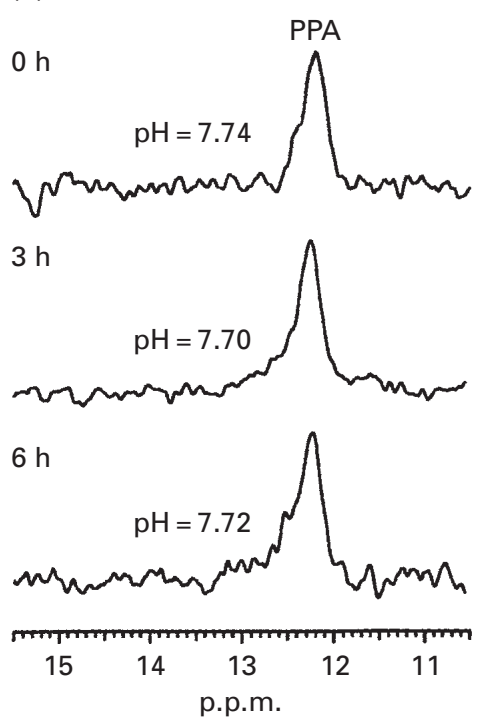

(b)
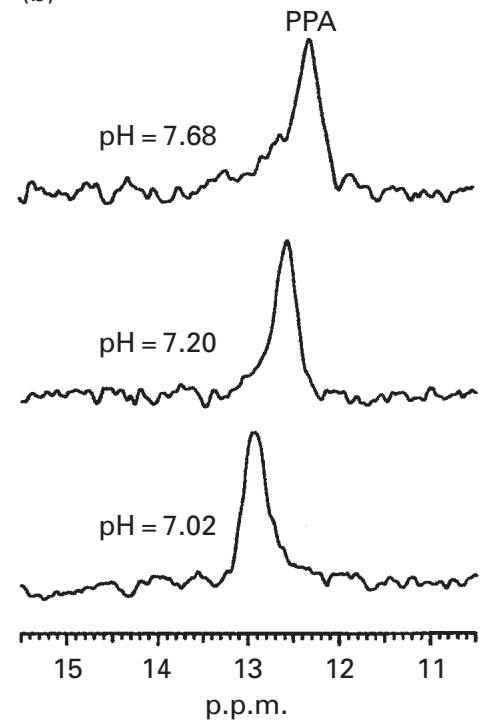

(c)
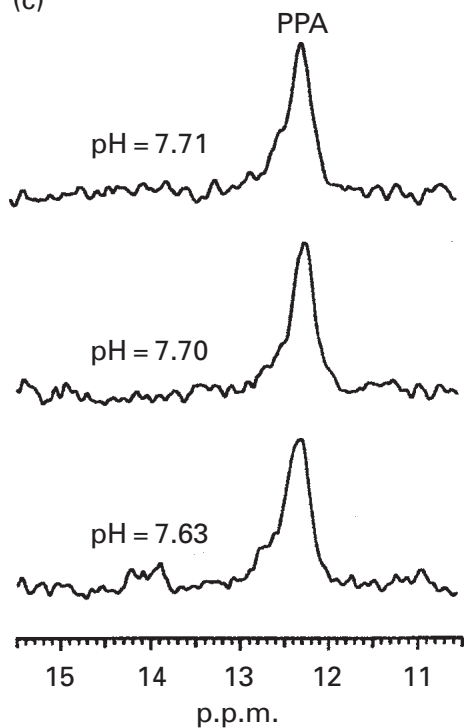

Fig. 1. ${ }^{31} \mathrm{P}-\mathrm{NMR}$ spectroscopy of rat spermatozoa during anaerobic incubation $(t=0,3$ and $6 \mathrm{~h})$ under three conditions: (a) spermatozoa from control rats in NMR medium lacking glucose; (b) spermatozoa from control rats in NMR medium

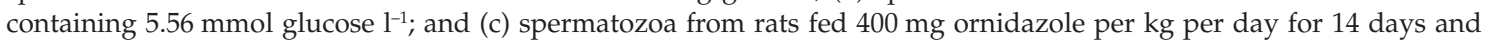

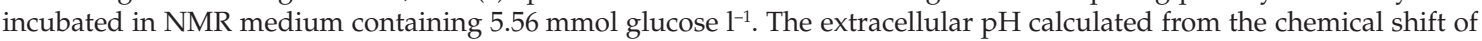
phenylphosphonate (PPA) is given at each time point for each condition.

(a)

$t=1.0 \mathrm{~h}$

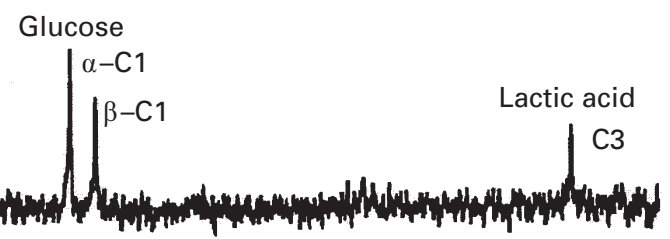

$t=7.5 \mathrm{~h}$

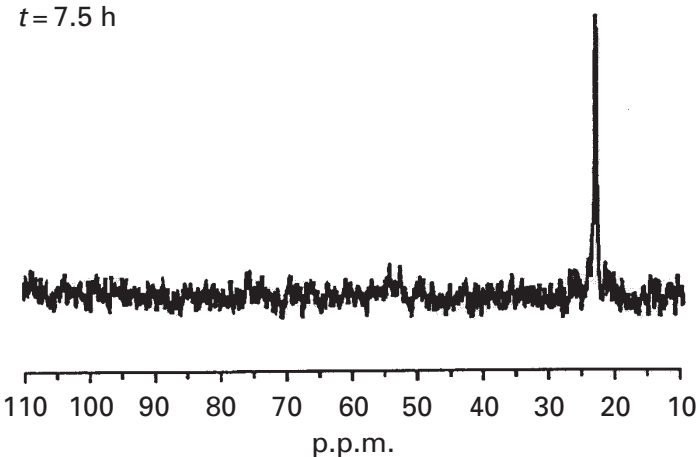

(b)

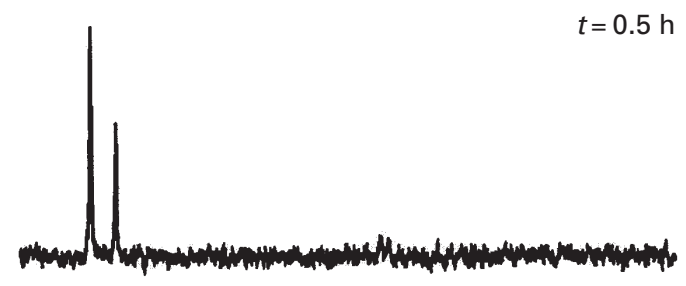

$t=7.0 \mathrm{~h}$

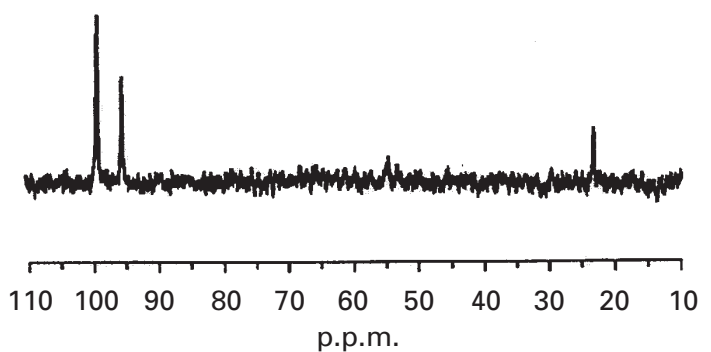

Fig. 2. ${ }^{13} \mathrm{C}-\mathrm{NMR}$ spectroscopy of spermatozoa from (a) control and (b) ornidazole-fed rats incubated for up to $7.5 \mathrm{~h}$. The position of signals in the spectrum originating from glucose ( $\alpha$ and $\beta \mathrm{C} 1$ carbons) and the C3 carbon of lactate are shown.

oocytes had 20-40 spermatozoa attached. In contrast, significantly fewer spermatozoa released from ornidazoletreated rats and incubated in glucose, or spermatozoa released from control rats and incubated in medium lacking glucose, were attached to the zona pellucida (Fig. 3).
Change of kinematic parameters of rat spermatozoa. During the zona pellucida binding assay, a different pattern of motility was observed in spermatozoa from the ornidazole-fed rats compared with the vehicle-treated rats at the time point of adding the oocytes to the sperm suspension $(5.5 \mathrm{~h}$ after 


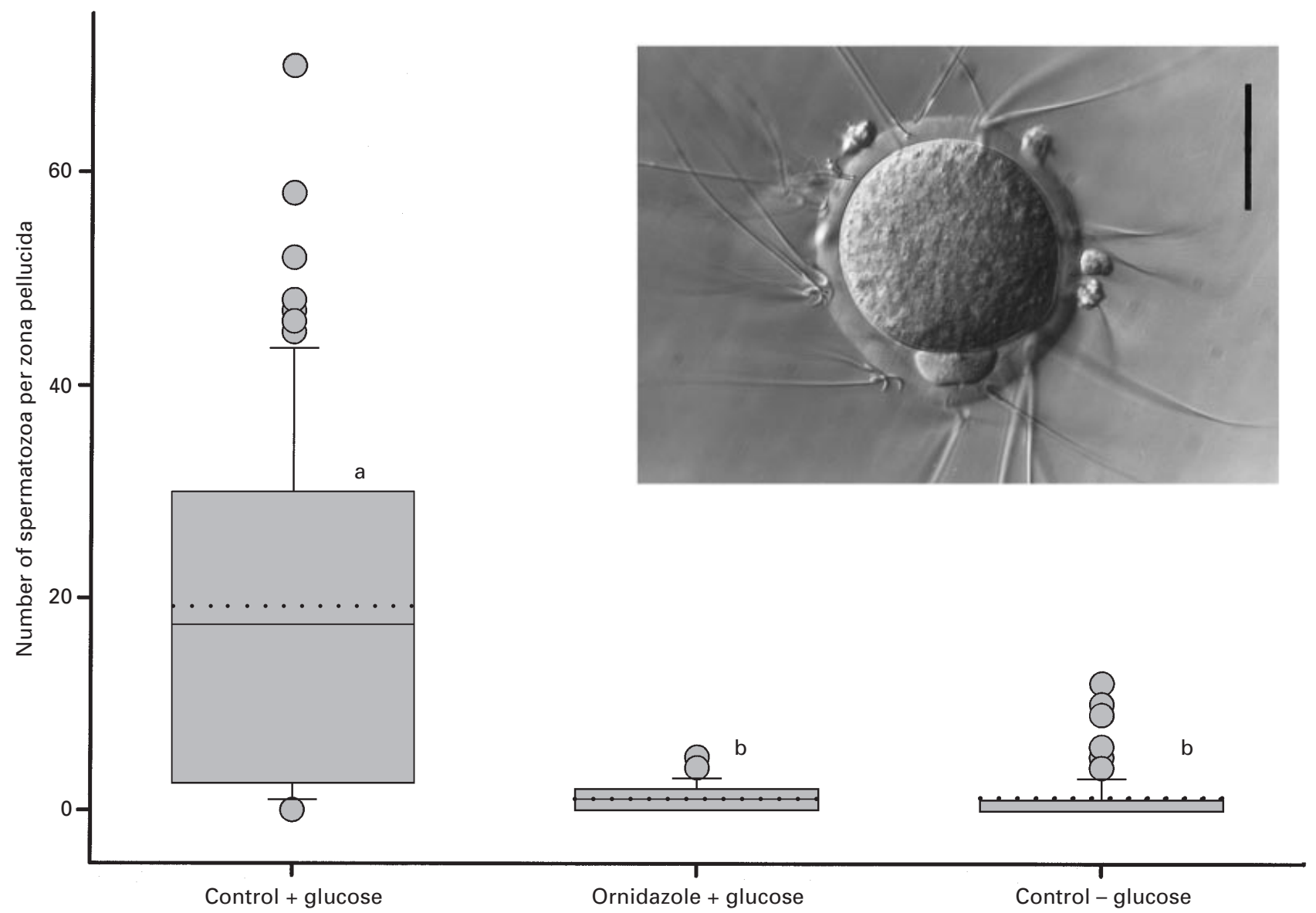

Fig. 3. Number of spermatozoa from the distal cauda epididymidis bound to the zona pellucida of rat eggs collected 45 min after insemination. Spermatozoa from four vehicle- (control) and four ornidazole-fed males ( $400 \mathrm{mg}$ per kg per day for 14 days) were pre-incubated for $5.5 \mathrm{~h}$ in normal IVF medium (with glucose and lactate) and spermatozoa from four control males were incubated in glucose-free medium. Box represents 25th and 75th percentiles, whiskers 10th and 90th, and the line the median. Outliers are indicated by circles. Plots bearing different letters are significantly different $(P<0.05)$. Inset shows a photomicrograph of a rat egg with several adherent control spermatozoa. Scale bar represents $50 \mu \mathrm{m}$.

releasing the spermatozoa from the epididymis). Samples from both groups were highly motile, but spermatozoa from the vehicle-treated rats appeared more active, moved jerkily and tended to swim in circular paths, whereas in spermatozoa from ornidazole-treated males the motion was smooth and progression was greater. Some spermatozoa in the control group displayed a highly curved flagellar bending, which, as a subjective observation, could not be quantified.

Spermatozoa from vehicle- and ornidazole-fed rats were incubated in IVF medium with and without glucose and the kinematic parameters were analysed by CASA over $8 \mathrm{~h}$ to quantify motility. During incubation, spermatozoa released from control animals in IVF-medium containing lactate, pyruvate and glucose showed a time-dependent decrease in VSL, linearity and straightness, and an increase in BCF, which was not observed when lactate and pyruvate only were present (Fig. 4). No difference in VCL was observed in the presence or absence of glucose. In contrast, spermatozoa from the ornidazole-fed rats displayed no differences in kinematic parameters depending on energy substrates and the values obtained were similar to those of control spermatozoa in the absence of glucose (Fig. 4). After 8 h, there was a significant decrease in VCL in the presence of glucose, but no change in the other parameters (ALH, wobble and VAP).

\section{Discussion}

The results of this study demonstrate a marked decrease in glycolytic turnover of spermatozoa in rats treated with antifertility doses of ornidazole and the consequences of such a block in glycolysis for the functions of spermatozoa that are required for fertilization. The results confirmed the inhibition of the sperm enzymes GAPDH and TPI by feeding ornidazole for 10 days as described by Oberländer et al. (1996) and showed an even greater inhibition of GAPDH after feeding ornidazole for 14 days. Further evidence for glycolytic inhibition was proved by NMR spectroscopy: the lack of a pH-shift under anaerobic conditions of incubation, indicating a markedly reduced glycolytic turnover, and the severely limited conversion of glucose to lactate. 

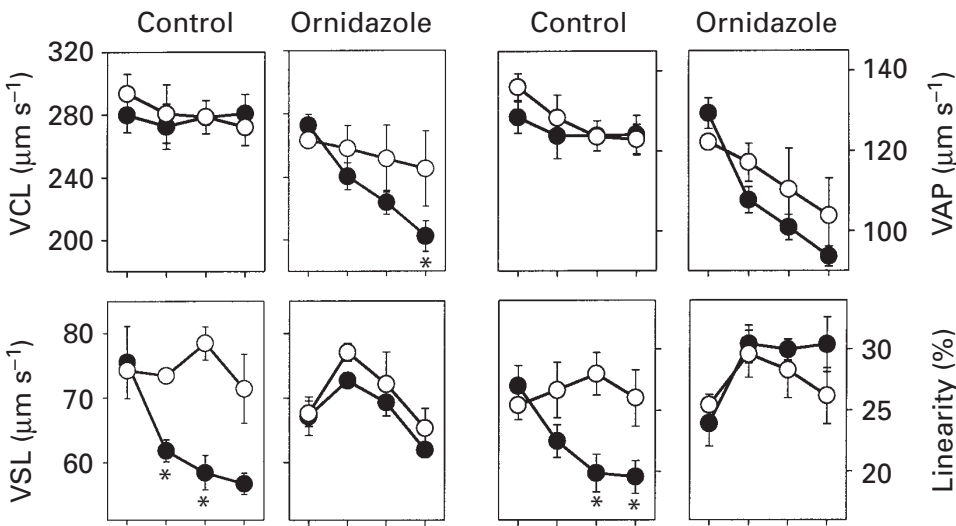

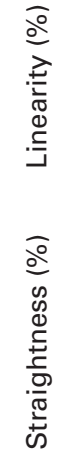
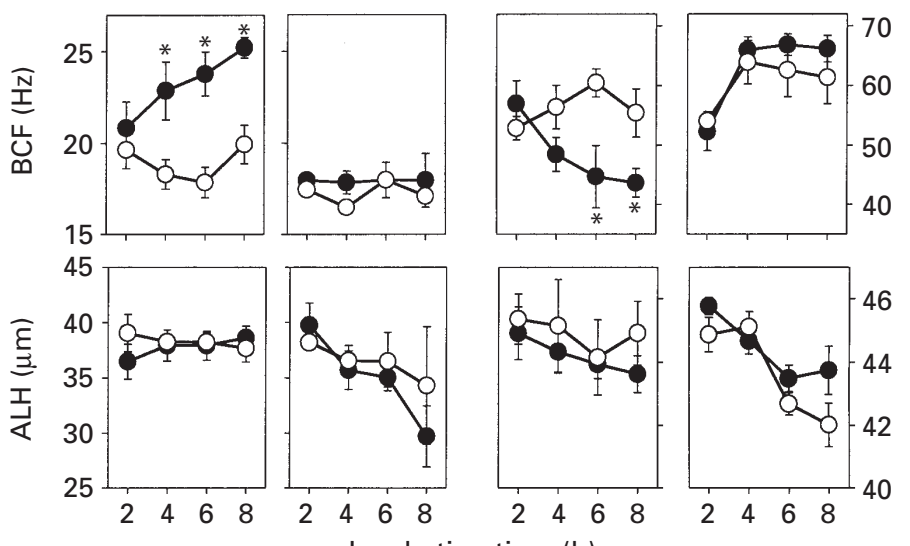

\section{$\frac{\frac{0}{0}}{\frac{0}{0}}$}

Fig. 4. Kinematic parameters of cauda epididymidal spermatozoa of vehicle(control) and ornidazole-treated (ornidazole) rats during $8 \mathrm{~h}$ incubation in IVF medium with $(\Theta)$ or without glucose $(\bigcirc)$. Values are means $\pm \operatorname{SEM}(n=3)$. Asterisks indicate significant differences between treatments at the same time point $(P<0.05)$. ALH: lateral head displacement; BCF: beat cross frequency; VAP: average path velocity; VCL: curvilinear velocity; VSL: straight line velocity.

Such glycolytic inhibition may explain the reduced sperm motility observed in vitro in the absence of lactate and pyruvate (Yeung et al., 1995; Cooper et al., 1997). However, the similar number of spermatozoa in the oviductal ampulla of females mated with ornidazole- and vehicle-treated rats (Yeung et al., 1995) indicates that the transport of spermatozoa to the fertilization site is not hindered, implying that the effect of ornidazole is on the fertilization process occurring in the ampulla. In the present study, IVF was used to demonstrate inhibition of fertilization by spermatozoa taken from ornidazole-treated rats, although the IVF medium contained the respiratory substrates lactate and pyruvate. These results are in agreement with the other studies (Tsunoda and Chang, 1975; Niwa and Iritani, 1978) in which IVF in rats failed in medium lacking glucose but containing lactate and pyruvate, and demonstrate the almost complete abolition of sperm glycolysis after feeding with ornidazole. It is possible that the spermatozoa were unable to overcome the mechanical resistance of the cumulus: Yeung et al. (1995) demonstrated a reduced number of spermatozoa within the cumulus oophorus of females mated to ornidazole-fed rats compared with controls, and Oberländer et al. (1994) highlighted the difficulty of sperm penetration in viscous media. However, this could not be proved in vitro, due to the removal of nearly all of the granulosa cells by the large number of spermatozoa used in the IVF procedure.

Theoretically, inhibition of hyaluronidase, a sperm enzyme involved in penetrating the cumulus in vivo (Lin et al., 1994; Myles and Primakoff, 1997) and binding to the zona pellucida (Overstreet et al., 1995; Hunnicutt et al., 1996), could mediate a block to fertilization, but this enzyme was not inhibited in the infertile ornidazole-fed rats. Removal of cumulus and granulosa cells before co-incubation of spermatozoa and oocytes failed to enable fertilization by spermatozoa from ornidazole-fed rats, revealing that neither the granulosa cells nor their secretions mediate the ornidazole-induced infertility. Since ornidazole inhibits the motility of spermatozoa in vitro (Bone et al., 1997), it is possible that ornidazole itself, or a metabolite, present in the epididymal fluid of the treated males, and transferred with the spermatozoa to the eggs, could exert direct effects on sperm-egg interaction in vitro. This was examined by adding epididymal fluid from the treated males to the IVF coculture. There was no evidence that the fluid was inhibitory, 
confirming that the infertility of ornidazole-treated rats is due to changes in the spermatozoa.

Examination of the inseminated eggs for evidence of fertilization revealed no spermatozoa from ornidazoletreated males beyond the zona pellucida. This is in agreement with the results of IVF in rats when glucose is absent from the medium (Tsunoda and Chang, 1975; Niwa and Iritani, 1978). Examination of the zonae pellucidae at 45 min after co-incubation with capacitated spermatozoa, when $80 \%$ of eggs are fertilized (Shalgi et al., 1983, 1986), revealed that the ability of spermatozoa from ornidazole-fed rats to bind to the zona pellucida in the presence of glucose was greatly impaired compared with control spermatozoa. This impairment was similar to that of control spermatozoa in the absence of glucose, indicating a requirement for glucose in binding to the zona pellucida in rats. The binding of spermatozoa to the zona pellucida in the present study resembled that reported by Gaddum-Rosse et al. (1984). In contrast, Urner and Sakkas (1996) showed that glucose is not required for binding of murine spermatozoa to the zona pellucida, and this could reflect differences in incubation conditions or species differences.

Another capacitation-related event, hyperactivation, may be inhibited by ornidazole treatment and thereby prevent fertilization. In rats, this is characterized by increased bending of higher amplitude (with prominent R-bend formation) and less forward progression (Shalgi and Phillips, 1988). A higher amplitude of bending could be observed in only a few control spermatozoa in glucose-containing IVF medium, whereas the forward progression was decreased. Examination by CASA revealed that control spermatozoa had lower VSL, straightness and linearity, and higher BCF, than spermatozoa incubated in the absence of glucose; there were no changes in VCL, VAP or ALH. The changes in linearity, VSL and BCF are in agreement with the observations by Cancel and Perreault (1998) for hyperactivated rat spermatozoa. Although the large flagellar bends, which are characteristic of hyperactivated motility of spermatozoa in several mammalian species (Yanagimachi, 1994; Si, 1997), were only rarely observed in control spermatozoa incubated in glucose-containing medium, the kinematic parameters evaluated may reflect hyperactivation of rat spermatozoa, as a result of the following: (i) the onset of this pattern of motility occurred at time points at which rat spermatozoa are capacitated (Shalgi and Kraicer, 1978); (ii) the decreased VSL was due to a tendency of spermatozoa to swim in circles, which reflects asymmetric bending, which is also characteristic of hyperactivation (Yanagimachi, 1994; Si, 1997); (iii) the spermatozoa appeared to be more vigorous, agile and jerky, as reflected in the increased BCF, which Yanagimachi (1994) considered to be more important in hyperactivation than a particular pattern of tail movements per se; and (iv) the changes in linearity, straightness, BCF and VSL (but not VCL) are in agreement with kinematic values for hyperactivated rat spermatozoa determined by Cancel and Perreault (1998). As spermatozoa from ornidazoletreated rats did not show this type of hyperactivated motility, even in the presence of glucose, glycolytic turnover must be required for hyperactivation of rat spermatozoa.

The dependence of hyperactivation on a glycolytic source of ATP, despite the inefficiency of this process compared with respiration (Hammerstedt and Lardy, 1983), may be a consequence of the peculiar compartmentation of energy metabolism within the flagellum. A sperm-specific isoenzyme of GAPDH (Welch et al., 1992; Bunch et al., 1998) is bound by covalent linkage to the fibrous sheath of the principal piece in a complex with TPI (Westhoff and Kamp, 1997; Bunch et al., 1998), whereas respiration is localized in the mid-piece. Mammalian spermatozoa have limited phosphagen (Kamp et al., 1996) that restricts their utilization of respiratory ATP. If the ATP formed in the principal piece is utilized in that location by dynein ATPases during hyperactivation, glycolysis may be crucial to recruitment of dynein-tubulin bridges in the axoneme which generates the high frequency, large bends that are characteristic of hyperactivation. Therefore, the failure of hyperactivation in spermatozoa from ornidazole-treated males may be explained by a local deprivation of ATP in the principal piece leading to low frequency, small bend, coordinated flagellation providing progressive motion rather than vigorous thrust. Thus, although inhibition of glycolysis would be unlikely to alter the total sperm ATP content (Ford and Harrison, 1987), it may be crucial to the failure of spermatozoa to develop sufficient force required for penetrating the zona pellucida.

This work was funded by the Deutsche Forschungsgemeinschaft Confocal Grant Ni-130/15 'The Male Gamete: Production, Maturation, Function' and Grant Co-142/1. The authors thank Martin Heuermann and Günther Stelke for animal care, and Joachim Esselmann for technical assistance. This work forms part of the work submitted for higher degrees by W. Bone and N. G. Jones.

\section{References}

Bergmeyer HU (1974) Methoden der Enzymatischen Analyse 496 pp Verlag Chemie, Weinheim

Bone W, Yeung CH, Skupin R, Haufe G and Cooper TG (1997) Toxicity of ornidazole and ornidazole analogues on rat sperm as reflected in motility parameters International Journal of Andrology 20 347-355

Bunch DO, Welch JE, Magyar PL, Eddy EM and O'Brien DA (1998) Glyceraldehyde 3-phosphate dehydrogenase-S protein distribution during mouse spermatogenesis Biology of Reproduction 58 834-841

Büsselmann G (1998) Untersuchungen zur Physiologie von Wirbeltierspermien mittels nicht-invasiver NMR- und Fluoreszenzspektroskopie sowie biochemischer Analysen PhD Thesis, University of Münster

Cancel A and Perreault SD (1998) CASA analysis of rat sperm incubated under capacitating conditions 8th International Symposium on Spermatology Montreal (Abstract 94)

Cooper TG, Yeung CH, Skupin R and Haufe G (1997) Antifertility potential of ornidazole analogues in male rats Journal of Andrology 18 431-438

Dorfman A (1955) Mucopolysaccharidases. In Methods in Enzymology pp 163-173 Eds SP Colowick and NO Kaplan. Academic Press, New York

Ford WCL and Harrison A (1987) Futile substrate cycles in the glycolytic pathway of boar and rat spermatozoa and the effect of $\alpha$-chlorohydrin Journal of Reproduction and Fertility 79 21-32

Ford WCL, Harrison A and Waites GMH (1981) Effects of 6-chloro-6deoxysugars on glucose oxidation in rat spermatozoa Journal of Reproduction and Fertility 63 67-73

Gaddum-Rosse P, Blandau RJ, Langley LB and Battaglia DE (1984) In vitro fertilization in the rat: observations on living eggs Fertility and Sterility 42 285-292

Hammerstedt RH and Lardy HA (1983) The effect of substrate cycling on the ATP yield of sperm glycolysis Journal of Biological Chemistry 258 8759-8768

Hochachka PW and Mommsen TP (1983) Protons and anaerobiosis Science 219 1391-1397 
Hunnicutt GR, Mahan K, Lathrop WF, Ramarao CS, Myles DG and Primakoff P (1996) Structural relationship of sperm soluble hyaluronidase to the sperm membrane protein PH-20 Biology of Reproduction 54 1343-1349

Jones AR and Cooper TG (1996) Metabolism of ${ }^{36} \mathrm{Cl}$-ornidazole after oral application to the male rat in relation to its antifertility activity Xenobiotica 27 711-721

Jones AR and Stevenson D (1983) Formation of the active antifertility metabolite of (S)-alpha-chlorohydrin in boar sperm Experientia 39 784-785

Jones AR, Stevenson D, Hutton P and Dawson AG (1981) The antifertility action of $\alpha$-chlorohydrin: metabolism by rat and boar sperm Experientia 37 $340-341$

Kamp G, Büsselmann G and Lauterwein J (1996) Spermatozoa: models for studying regulatory aspects of energy metabolism Experientia 52 487-494

Leese HJ (1988) The formation and function of oviduct fluid Journal of Reproduction and Fertility $\mathbf{8 2}$ 843-856

Lin Y, Mahan K, Lathrop WF, Myles DG and Primakoff P (1994) A hyaluronidase activity of the sperm plasma membrane protein $\mathrm{PH}-20$ enables sperm to penetrate the cumulus cell layer surrounding the egg Journal of Cell Biology 125 1157-1163

McClain RM and Downing JC (1988a) Reproduction studies in rats treated with ornidazole Toxicology and Applied Pharmacology 92 480-487

McClain RM and Downing JC (1988b) The effect of ornidazole on fertility and epididymal sperm function in rats Toxicology and Applied Pharmacology 92 488-496

Myles DG and Primakoff P (1997) Why did the sperm cross the cumulus? To get to the oocyte. Functions of the sperm surface proteins $\mathrm{PH}-20$ and fertiliin in arriving at, and fusing with, the egg Biology of Reproduction 56 320-327

Niwa K and Iritani A (1978) Effect of various hexoses on sperm capacitation and penetration of rat eggs in vitro. Journal of Reproduction and Fertility 53 267-271

Oberländer G, Yeung CH and Cooper TG (1994) Induction of reversible infertility in male rats by oral ornidazole and its effects on sperm motility and epididymal secretions Journal of Reproduction and Fertility 100 551-559

Oberländer G, Yeung CH and Cooper TG (1996) Influence of oral administration of ornidazole on capacitation and the activity of some glycolytic enzymes of rat spermatozoa Journal of Reproduction and Fertility $106231-239$

Overstreet JW, Lin Y, Yudin AI, Meyers SA, Primakoff P, Myles DG, Katz DF and Vandevoort CA (1995) Location of the PH-20 protein on acrosomeintact and acrosome-reacted spermatozoa of cynomolgus macaques Biology of Reproduction 52 105-114

Schwartz DE, Jordan J-C, Vetter W and Oesterhelt G (1979) Metabolic studies of ornidazole in the rat, in the dog and in man Xenobiotica 9 571-581
Shalgi R and Kraicer PF (1978) Timing of sperm transport, sperm penetration and cleavage in the rat Journal of Experimental Zoology 204 353-360

Shalgi R and Phillips DM (1988) Motility of rat spermatozoa at the site of fertilization Biology of Reproduction 39 1207-1213

Shalgi R, Kaplan R and Nebel L (1983) The capacitation rate of rat sperm in vitro. In The Sperm Cell pp 47-50 Ed. J Andre. Martinus Nijhoff Publishers, The Hague

Shalgi R, Matityaha A and Nebel L (1986) The role of carbohydrates in sperm-egg interaction in rats Biology of Reproduction 34 446-452

Si Y (1997) Hyperactivated motility of mammalian sperm (Update) Advances in Contraceptive Delivery Systems 13 101-116

Smith MB, Babcock DF and Lardy HA (1985) A ${ }^{31}$ PNMR-study of the epididymis and epididymal sperm of the bull and hamster Biology of Reproduction 33 1029-1040

Stevenson D and Jones AR (1985) Production of (S)-3-chlorolacaldehyde from (S)- $\alpha$-chlorohydrin by boar spermatozoa and the inhibition of glyceraldehyde 3-phosphate dehydrogenase in vitro. Journal of Reproduction and Fertility 74 157-165

Toyoda Y and Chang MC (1974) Fertilization of rat eggs in vitro by epididymal spermatozoa and the development of eggs following transfer Journal of Reproduction and Fertility 36 9-22

Tsunoda Y and Chang MC (1975) In vitro fertilization of rat and mouse eggs by ejaculated sperm and the effect of energy sources on in vitro fertilization of rat eggs Journal of Experimental Zoology 193 79-86

Urner F and Sakkas D (1996) Glucose is not essential for the occurrence of sperm binding and zona pellucida-induced acrosome reaction in the mouse International Journal of Andrology 19 91-96

Welch JE, Schatte EC, O'Brien DA and Eddy EM (1992) Expression of a glyceraldehyde 3-phosphate dehydrogenase gene specific to mouse spermatogenic cells Biology of Reproduction 46 869-878

Westhoff D and Kamp G (1997) Glyceraldehyde 3-phosphate dehydrogenase is bound to the fibrous sheath of mammalian spermatozoa Journal of Cell Science 110 1821-1829

Yanagimachi R (1994) Mammalian fertilization. In The Physiology of Reproduction 2nd Edn pp 189-317 Eds E Knobil and JD Neill. Raven Press, New York

Yeung CH, Oberländer G and Cooper TG (1992) Characterization of the motility of rat spermatozoa by computer-aided objective measurement Journal of Reproduction and Fertility 96 427-441

Yeung CH, Oberländer G and Cooper TG (1995) Effects of the male antifertility agent ornidazole on sperm function in vitro and in the female genital tract Journal of Reproduction and Fertility 103 257-264 